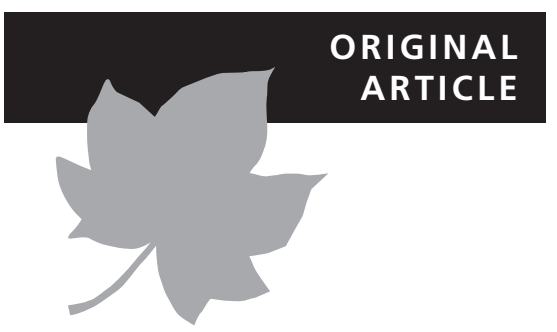

\title{
Flower visitation by European birds offers the first evidence of interaction release in continents
}

\author{
Luís P. da Silva ${ }^{1,2_{\star}}$, Jaime A. Ramos ${ }^{1}$, António Pereira Coutinho ${ }^{2}$,
} Paulo Q. Tenreiro ${ }^{3}$ and Ruben H. Heleno ${ }^{2}$

${ }^{1}$ MARE - Marine and Environmental Sciences Centre, Department of Life Sciences, University of Coimbra, 3000-456 Coimbra, Portugal, ${ }^{2}$ CFE - Centre for Functional Ecology, Department of Life Sciences, University of Coimbra, 3000-456 Coimbra, Portugal, ${ }^{3}$ ICNF - Instituto da Conservação da Natureza e das Florestas, Departamento de Conservação da Natureza e Florestas do Centro, 3000-611 Coimbra, Portugal
*Correspondence: Luís P. da Silva, CFE Centre for Functional Ecology, Department of Life Sciences, University of Coimbra, Calçada Martim de Freitas, 3000-456 Coimbra, Portugal.

E-mail: lfpascoals@gmail.com

\section{ABSTRACT}

Aim All species are imbedded in a network of interactions with other species, which define an important component of their ecological niche. These interactions are dynamic and can change the emergence of vacant niches in the environment. Niche adjustments have been predicted to be particularly common on insular communities as a response to the poor and disharmonic biota of oceanic island - the interaction release hypothesis, however, the phenomena has not yet been reported on continents. Taxonomic groups of specialized nectarivorous birds are present on all continents except in Europe where they became extinct in the Oligocene, likely leaving behind underexplored flower resources. We performed the first community-level assessment of flower visitation by European birds to evaluate if insectivorous and granivorous birds show an interaction release towards consuming flower resources in Europe.

Location Larçã - Coimbra, Portugal, Europe.

Methods During one year, we collected pollen loads from the forehead of 634 birds. Pollen loads were prepared by acetolysis and all pollen grains were identified under a microscope. All interactions were compiled into a quantitative interaction matrix describing the first pollen-transport network by European birds.

Results One-fifth of the bird individuals, corresponding to two thirds of the bird species sampled carried pollen from 45 different types. The vast majority of the plant species found were native but the alien Eucalyptus globulus was by far the species most commonly found in the birds' pollen loads. Overall, the structure of the pollen-transport network from Europe shared many attributes of other networks that include taxonomic groups of specialized nectarivorous birds.

Main conclusions We show that the interaction release hypothesis is not exclusive to insular communities but can also be observed in continents, greatly increasing the potential geographical distribution of this phenomenon. However, it seems considerably less pronounced in Europe than in the Galápagos, where it was first described, probably due to the much stronger selective pressures on the simplified ecosystems of oceanic islands.

\section{Keywords}

bird-flower interactions, ecological niche, ecological release, mutualistic networks, pollen transport, resource opportunity, rewiring, trophic niche

\section{INTRODUCTION}

All species are imbedded in an intricate web of interactions upon which they depend to survive and reproduce (Tylianakis, 2008). These inter-specific interactions form a fundamental component of each species ecological niche the Eltonian niche (Elton, 1927). Obviously, these interactions are not static but they constantly change in response to environmental alterations, such as the colonization of remote sites, the arrival of new competitors or the local extinction of 
co-occurring species (Cox \& Ricklefs, 1977; Keane \& Crawley, 2002; Refsnider et al., 2015). Specifically, when a species experiences a reduction in the pressure from competitors, predators or parasites, it frequently expands its niche by increasing its population size, expand its distribution area, and including new items in its diet, a phenomena known as ecological release (Cox \& Ricklefs, 1977; Bolnick et al., 2010; Refsnider et al., 2015). A particular case of ecological release has been documented on oceanic islands, which are characterized by disharmonic biotas and overall low species richness, as a result of long-distance dispersal limitations (Whittaker \& Fernández-Palacios, 2007; Heleno \& Vargas, 2015). On the other hand, the few species that successfully colonize islands, free from their continental natural competitors often sustain large population densities (Cox \& Ricklefs, 1977). The interaction release hypothesis postulates that in this particular conditions of high intraspecific competition and available empty niches due to dispersal filtering, insular animals can expand their classic trophic niche in order to include underexplored resources (Traveset et al., 2015). A remarkable example is the massive shift of Galápagos land bird species that expanded their initially insectivorous and granivorous diets in order to consume nectar and pollen from flowers, as a response to low insect abundance in these islands (Traveset et al., 2015). While this hypothesis was developed considering the typical biological disharmony of oceanic islands, comparable high-quality data sets accessing pollen transport by birds on continental communities are still lacking, and therefore it is still not clear if this is strictly an island phenomena (Traveset et al., 2015).

Taxonomic groups of specialized nectarivorous birds are present on all continents except Europe, namely: hummingbirds (Trochilidae Vigors, 1825) and tanagers (Thraupidae Cabanis, 1847) in the Americas, sunbirds (Nectariniidae Vigors, 1825) in Africa and southern Asia, honeyeaters (Meliphagidae Vigors, 1825) in Oceania, sugar-birds (Promeropidae Vigors, 1825) in southern Africa, honeycreepers (Drepanidini James, 2004) in Hawaii, flowerpeckers (Dicaeidae Bonaparte, 1853) and lories (Loriini Selby, 1836) in south-eastern Asia and Oceania (del Hoyo et al., 2016). Nevertheless, the fossil record indicates the presence of taxonomic groups of nectarivorous birds in Europe, at least until the early Oligocene, that is, 30 million years ago (Mayr, 2004; Louchart et al., 2008). These birds very likely fed actively on flowers (Mayr \& Wilde, 2014) and their extinction likely left an ecological opportunity of available flower resources that could be explored by other unspecialized taxonomic groups of nectarivorous birds. Flowers, and particularly nectar, represent an abundant and valuable resource in many regions of the world, and therefore it is no surprise that even birds without specific adaptations for nectar consumption try to explore flower resources when they are available (da Silva et al., 2014). Indeed, several studies report this opportunistic behaviour on insectivorous and granivorous birds (e.g. Ortega-Olivencia et al., 2005; da Silva et al., 2014; Calviño-Cancela \& Neumann, 2015). However, these records come from taxonomically or temporal restricted studies not encompassing whole communities (Cecere et al., 2011; Ortega-Olivencia et al., 2012; Wood et al., 2014; Calviño-Cancela \& Neumann, 2015). Therefore, we are still largely ignorant of the extent of this phenomenon at the community level, which is the appropriate organizational level to detect an interaction release (Traveset et al., 2015), and thus unable to understand if the phenomenon is geographically restricted to island communities or if it can also occur on the more complex continental communities. Ecological networks provide a powerful tool to explore communitylevel patterns, by considering simultaneously community composition, structure and function (Heleno et al., 2014); however, they require an intensive field sampling, which practically hinders large scale replication (Heleno et al., 2014). Here, we build the first year-round and community wide, bird-flower interaction network on a continent to look for evidence of an interaction release of a European bird community as a response to the absence of taxonomic groups of specialized nectarivorous birds. We hypothesize that an interaction release might have occurred in Europe, and therefore that a considerable proportion of birds will carry pollen of several plant species. Given the alternative food sources provided by the complex habitat structure in Europe and the competition for flowers from insects, we expect some consumption of flower resources by insectivorous and granivorous birds, mainly during periods of main food shortage, for example, winter, but not as high as that reported for the Galápagos Islands, where the phenomenon was first described (Traveset et al., 2015).

\section{MATERIALS AND METHODS}

\section{Study area}

The study was performed in a secondary native forest in Larçã $\left(40^{\circ} 19^{\prime} \mathrm{N} ; 8^{\circ} 24^{\prime} \mathrm{W}\right)$ near Coimbra, central Portugal, under a mediterranean climate influence, with hot and dry summers and mild winters. The forest in Larçã resulted from the gradual replacement of an old Pinus pinaster Aiton plantation by autochthonous vegetation, forming a dense mediterranean scrubland, dominated by Arbutus unedo L. and Quercus faginea Lam., with some pines left. The landscape surrounding the study site is mainly composed a mosaic agricultural and rural areas, small patches of oak (Quercus spp.) and pine (Pinus spp.) trees with native mediterranean shrubs and of Eucalyptus globulus Labill. plantations (c. $500 \mathrm{~m}$ from our study site).

\section{Data collection}

Birds were captured twice per month between June 2013 and May 2014 using Ecotone mist nets (Gdynia, Poland). Birds were ringed and released after pollen collection. Pollen loads were collected by cutting a few feathers from the birds' forehead and directly stored in sterile Eppendorf tubes. Samples were prepared by acetolysis (Erdtman, 1960) and mounted in glycerine jelly on three microscope slides. Due to the high 
viscosity of the mounting solution, c. $20 \%$ of the solution was lost by adherence to walls of the tubes during preparation of the samples (da Silva et al., 2016). All slides were scanned under a light microscope at $1000 \times$ magnifications to identify and quantify all pollen grains. Pollen was identified to the lowest possible taxa, most frequently to species or genus, but sometimes to a morphopollinic group. Morphological characters as shape, exine sculpture, number and type of aperture, etc., were compared to a reference collection and specialized literature (Kapp, 1969; Moore \& Webb, 1978; Belmonte et al., 1986; Valdés et al., 1987; Mateus, 1989; Reille, 1992; Queiroz, 2012).

\section{Data analysis}

All interactions between bird species and pollen types were compiled into a single quantitative interaction matrix. No direct observations of feeding birds were performed during this study. We considered an interaction when intact pollen was found in a sample (Traveset et al., 2015). In addition, we built a more conservative interaction matrix by excluding all interactions with less than five pollen grains of any specific type, and thus potential contaminations, see Banza et al. (2015). In the cases where a plant was not identified to the species level but to a higher taxonomic level, it was considered native if any representative of those taxa occurs naturally in the region. Bird trophic guilds were determined according to del Hoyo et al. (2016) as insectivores, granivores and omnivores. The data set was sorted into four main seasons: summer (from June to August), autumn (September to November), winter (December to February) and spring (March to May). An evaluation of the level of sampling completeness for species was performed by implementing the Chao asymptotic richness estimator (Chao, 1987) in package 'vegan' (Oksanen et al., 2016) for R 3.2.2 (R Core Team, 2016). To analyse the importance of each bird feeding trophic guild and plant origin in the network structure, the following species-level descriptors were calculated: linkage level, that is, the number of species in the network with which a focal species interacts; species strength, a measure of a species' importance across all its partners (Bascompte et al., 2006); and specialization index (d'), describing the level of selectiveness for partners of each species (Blüthgen et al., 2006). In order to evaluate how the structure of the assembled bird-flower network is related to other previously described bird-flower networks, the following network structure descriptors were calculated: connectance, that is, the proportion of realized links from all possible links (Jordano, 1987); weighted nestedness (WNODF), indicating the degree to which the interactions of the most specialist species are nested within the partners of the most generalists (AlmeidaNeto \& Ulrich, 2011); interaction evenness, measuring the Shannon's evenness of interaction frequencies (Bersier et al., 2002); network specialization index $\left(\mathrm{H}_{2}^{\prime}\right)$, that is, the degree of network selectiveness as the departure from a theoretical non-discrimination of interactions (Blüthgen et al., 2006); and modularity $(\mathrm{Q})$, evaluating the presence of clusters of strongly interacting species using the QuanBiMo algorithm (Dormann \& Strauss, 2014). As the QuanBiMo can produce slightly different modularity estimates between runs, we performed 100 independents runs set to $10^{8}$ swaps of the network and selected the highest modularity (Valverde et al., 2016). Network analyses were performed using package 'bipartite' (Dormann et al., 2008) in R 3.2.2.

We compared our European bird-flower network with the only other available network of pollen transport by taxonomic groups of unspecialized nectarivorous birds, that of Galápagos (Traveset et al., 2015), and also with other birdflower networks which include both specialized and unspecialized taxonomic groups of nectarivorous birds. Because the majority of bird-flower network metrics available in the literature had qualitative descriptors (Traveset et al., 2015; Vizentin-Bugoni et al., 2016) we also calculate the qualitative versions of nestedness (NODF) and modularity (M), with software Aninhado 3.0.3 (Guimarães \& Guimarães, 2006) and Netcarto (Guimerà \& Amaral, 2005) respectively. The level of network specialization $\left(\mathrm{H}_{2}{ }^{\prime}\right)$ was further compared with that of the networks described in Dalsgaard et al. (2011), Maruyama et al. (2014) and Vizentin-Bugoni et al. (2016). The significance of the network metrics was assessed by comparing the observed values to those from 1000 networks assembled under null model vaznull in package bipartite and model Ce in Aninhado. Comparisons of species-level network descriptors between bird guilds (insectivores, granivores and omnivores), plant's origin (native or alien), and season (summer, autumn, winter and spring) were performed with general linear models (GLMs), with a significance level of $\alpha<0.05$ with the package 'Ime4' (Bates et al., 2015) in R 3.2.2. Undetermined pollen types, that is, types without identification of the plant family, representing 3\% of all interactions, are shown in Table 1 , but were excluded from the comparisons. Data are presented as mean $\pm \mathrm{SD}$.

\section{RESULTS}

Overall, 634 individual birds from 31 species were sampled and pollen grains were found on 129 of these birds (20\%) from 21 species (68\%; Fig. 1). A total of 45 different pollen types were found, of which half $(51 \%)$ were identified to the genus or species level and the remaining were identified to the family or to a morphopollinic group, that in most cases represent groups from known plant families (Table 1). Therefore, the resulting network quantifies 105 links between birds and plant species (Fig. 2). Our sampling detected $84 \%$ of the bird species and $63 \%$ of the pollen types estimated by the Chao asymptotic richness estimator. In the conservative approach, that is, only considering interactions represent by at least five pollen grains, the resulting network quantified 31 links between 18 pollen types and nine bird species (see Appendix S1 in Supporting Information).

Most interactions were detected in winter (GLM: $t=2.176, \quad P=0.042)$ and there were no significant 
L. P. da Silva et al.

Table 1 Origin, pollinator agent, flowering season and number of samples for each plant taxa or pollen type transported by birds in the Larçã-Portugal network.

\begin{tabular}{|c|c|c|c|c|}
\hline Origin & Lower taxa or pollen type & Pollinator agent & Flowering season & Number of samples \\
\hline \multirow[t]{3}{*}{ Alien } & Cupressus sp. & Wind & Winter and spring & 2 \\
\hline & Eucalyptus globulus Labill. & Animal & Late autumn to early spring & 68 \\
\hline & Cedrus sp. & Wind & Autumn to mid spring & 18 \\
\hline \multirow[t]{38}{*}{ Native } & Viburnum sp. & Animal & Mid winter to spring & 1 \\
\hline & Amaranthaceae Juss. & Wind & Spring to autumn & 2 \\
\hline & Pistacia sp. & Wind & Spring & 1 \\
\hline & Hedera sp. & Animal & Autumn & 1 \\
\hline & Asparagaceae Juss. or Amaryllidaceae J.St.-Hil. & Animal & Winter to summer & 1 \\
\hline & Anthemideae Cass. & Animal & Spring to summer & 3 \\
\hline & Cichorieae Cassini & Animal & Mid spring to summer & 2 \\
\hline & Cynareae Lam. \& DC. & Animal & Mid spring to summer & 3 \\
\hline & Alnus sp. & Wind & Winter early spring & 1 \\
\hline & Betula sp. & Wind & Spring & 1 \\
\hline & $\begin{array}{l}\text { Brassicaceae type Capsella bursa-pastoris (L.) Medik. } \\
\text { Brassicaceae type }\end{array}$ & Animal & Winter to mid summer & 5 \\
\hline & $\begin{array}{l}\text { Raphanus raphanistrum } \mathrm{L} . \\
\text { Brassicaceae type }\end{array}$ & Animal & Winter to mid summer & 7 \\
\hline & Sinapis arvensis $\mathrm{L}$. & Animal & Spring to mid summer & 5 \\
\hline & Caryophyllaceae & Animal & Late winter to summer & 1 \\
\hline & Cistaceae type & & & \\
\hline & Cistus ladanifer $\mathrm{L}$. & Animal & Late winter to mid summer & 1 \\
\hline & Cistaceae type Halimium halimifolium (L.) Willk. & Animal & Late winter to mid summer & 2 \\
\hline & Arbutus unedo L. & Animal & Autumn to mid winter & 1 \\
\hline & Calluna vulgaris (L.) Hull & Animal & Late summer to autumn & 2 \\
\hline & Erica arborea $\mathrm{L}$. & Animal & Late winter to mid summer & 4 \\
\hline & Erica lusitanica Rudolphi & Animal & Winter and spring & 3 \\
\hline & Erica scoparia L. & Animal & Mid spring to early summer & 2 \\
\hline & Cytisus sp. & Animal & Mid winter to mid summer & 1 \\
\hline & Quercus sp. & Wind & Spring & 12 \\
\hline & Lamiaceae type & & & \\
\hline & $\begin{array}{l}\text { Mentha aquatica } \mathrm{L} \text {. } \\
\text { Lamiaceae type }\end{array}$ & Animal & Summer to mid autumn & 1 \\
\hline & Salvia verbenaca $\mathrm{L}$. & Animal & Late winter to early summer & 1 \\
\hline & Olea europaea L. & Wind & Mid spring to early summer & 1 \\
\hline & Phillyrea latifolia L. & Wind & Winter to mid spring & 2 \\
\hline & Pinus sp. & Wind & Spring & 30 \\
\hline & Plantago sp. & Wind & Spring and summer & 1 \\
\hline & Poaceae & Wind & Spring and summer & 7 \\
\hline & Rhamnus alaternus $\mathrm{L}$. & Animal & Mid winter to mid spring & 6 \\
\hline & Prunus sp. & Animal & Mid winter to early summer & 5 \\
\hline & Rubus sp. & Animal & Summer & 3 \\
\hline & Rosaceae type 1 & Animal & Late winter to summer & 1 \\
\hline & Rosaceae type 2 & Animal & Late winter to summer & 2 \\
\hline & Salix sp. & Wind and animal & Mid winter to summer & 4 \\
\hline \multirow[t]{6}{*}{ Unknown } & Unknown type 1 & Unknown & Unknown & 2 \\
\hline & Unknown type 2 & Unknown & Unknown & 1 \\
\hline & Unknown type 3 & Unknown & Unknown & 1 \\
\hline & Unknown type 4 & Unknown & Unknown & 1 \\
\hline & Unknown type 5 & Unknown & Unknown & 1 \\
\hline & Unknown type 6 & Unknown & Unknown & 1 \\
\hline
\end{tabular}

differences on the presence of pollen throughout the other three seasons. The most frequently captured bird species, Sylvia atricapilla Linnaeus, 1758, was also the species that most frequently carried pollen, representing $49 \%$ of the individuals with pollen (Fig. 1). Pollen loads had an average of 568 pollen grains $(S D=1980 ; \quad$ Min. $=1, \quad$ Max. $=13,008)$.
Approximately one-third of the pollen loads (30\%) were mixed, that is, had pollen of more than one type $(1.7 \pm 1.5$, Min. $=1$, Max. $=10$ pollen types per sample). Native plants species represented most of the interactions (57\%). Nevertheless, approximately half (53\%) of the samples with pollen contained pollen of the alien tree species, E. globulus, which 
Figure 1 Number of birds captured and presence and diversity of pollen grains found on each bird species in the LarçãPortugal network. Notice the logarithmic scale. Bird species are ordered by abundance.
Figure 2 Quantitative pollen transport network by taxonomic groups of unspecialized nectarivorous birds in Larçã, Portugal, representing the interactions between 21 bird species and 45 pollen types (morphospecies). The size of each node is proportional to the number of links (i.e. linkage level), and the width of the links is proportional to the frequency of the interaction (i.e. number of bird samples containing pollen grains of each type). The letter represent the pollinator agent of the respective plant: $\mathrm{w}$-wind and a-animal.
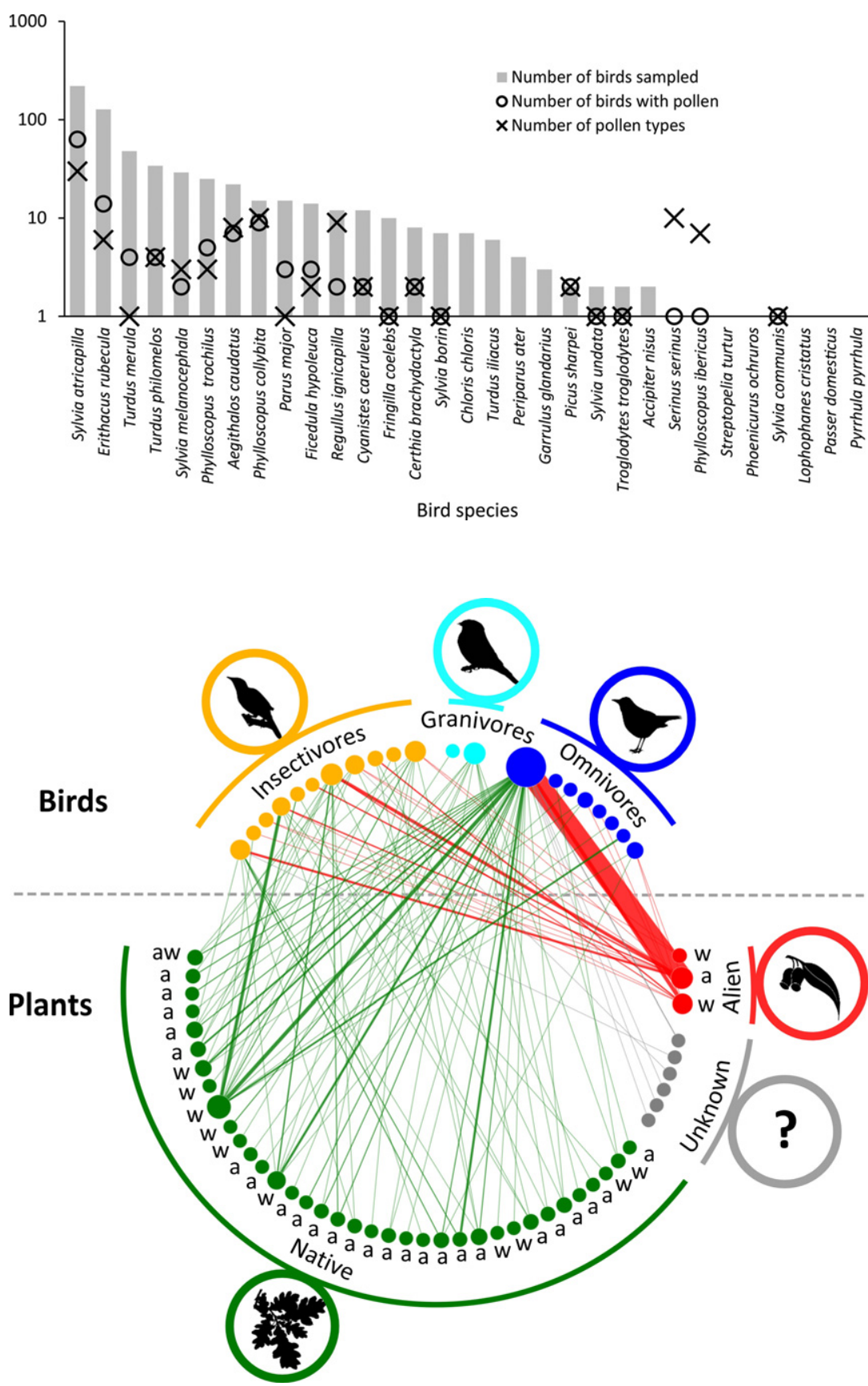

alone represented $31 \%$ of all detected interactions (Table 1). On average, each bird species carried pollen of five different types $($ Min. $=1$; Max. $=30)$ and each pollen type was dispersed by 2.3 bird species (Min. = 1; Max. = 12).

We found no differences on the interaction patterns established by the three bird guilds. On average, alien plant species were present on more samples (GLM: $t=-2.401$, $P=0.021$ ), were dispersed by more bird species (GLM: $t=-2.449, P=0.019)$ and had a higher species strength (GLM: $t=-2.731, P=0.010$ ) than native plants, but they did not differ in their specialization level d' (GLM: $t=-0.532, P=0.598)$. Network specialization $\left(\mathrm{H}_{2}{ }^{\prime}\right)$ was low but not significantly different from the null model expectation $\left(\mathrm{H}_{2}{ }^{\prime}=0.21, P=0.146\right)$, while interaction evenness was significantly lower than that of the null models (IE $=0.58, \quad P=0.001)$. Connectance was generally low (11.1\%) and was not confronted to a null model expectation (which assumes fixed connectance). The qualitative (unweighted/binary links) network was significantly nested $(\mathrm{NODF}=37.80, P<0.001)$ and was not modular $(M=0.46$, $P=0.333$ ), while the quantitative network (weighted links) was not significantly nested (WNODF $=21.45, P=0.414)$ but was significantly modular $(Q=0.33, P<0.016)$.

When comparing the structure of the European network described here, with the structure of other bird-flower networks available in the literature, including that from the 


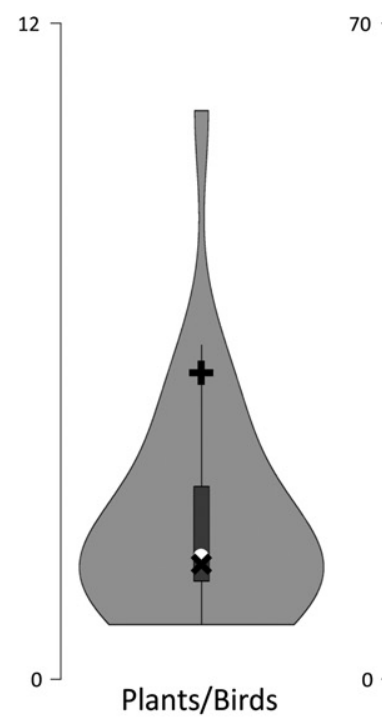

Plants/Birds

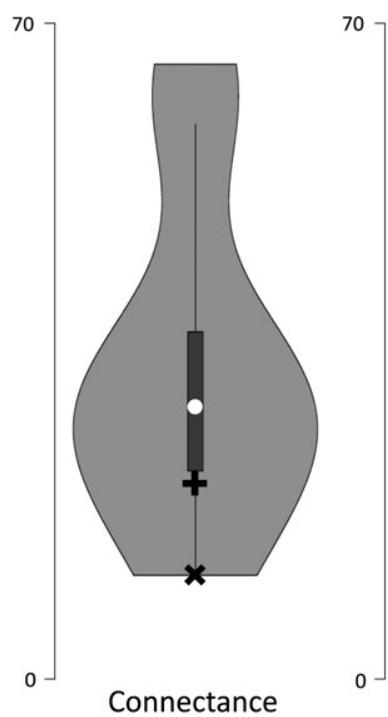

Connectance
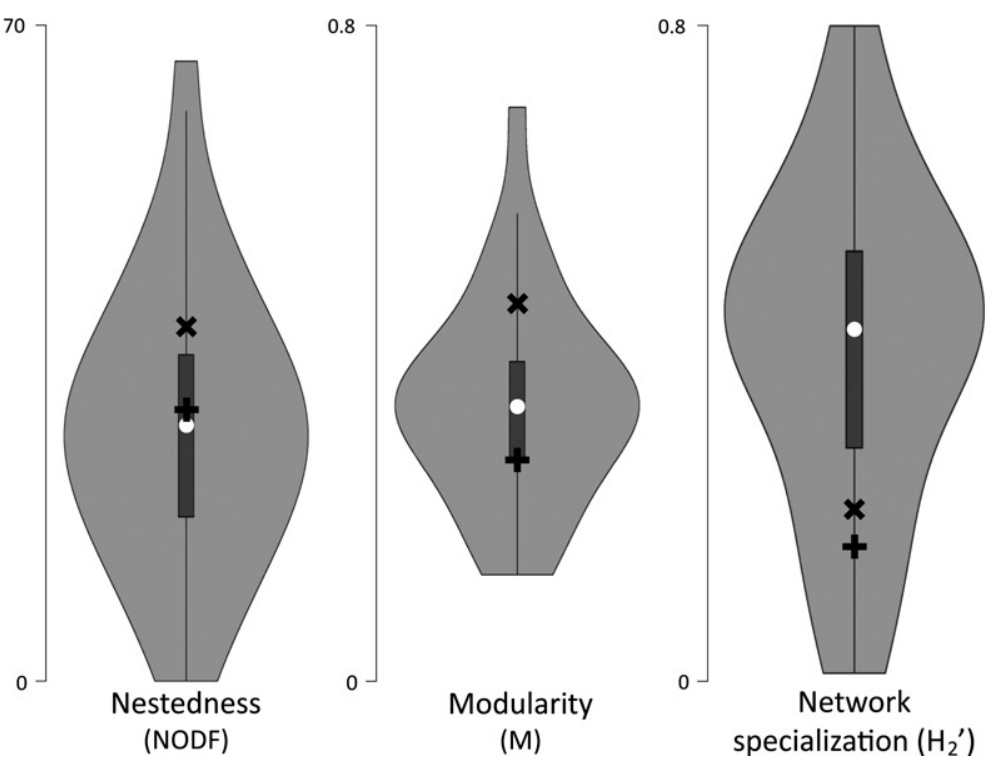

Figure 3 Violin plots showing how the structure of the pollen-transport network by taxonomic groups of unspecialized nectarivorous birds reported here (represented by an X), relates with similar networks by taxonomic groups of specialized nectarivorous birds reported around the world and also with the Galápagos network of unspecialized nectarivorous birds (represented with a + ). The white circle represents the median, the dark grey box represents the 25th and 75th percentiles, the middle line the upper and lower adjacent values and the light grey represents the kernel density of all data points (Hintze \& Nelson, 1998). The plants/birds ratio, connectance, nestedness (NODF) and qualitative modularity (M) were based on the data provided in Traveset et al. (2015) and Vizentin-Bugoni et al. (2016), while network specialization $\left(\mathrm{H}_{2}{ }^{\prime}\right)$ also included the data provided in Dalsgaard et al. (2011) and Maruyama et al. (2014).

Galápagos Islands, we observe that for nearly all descriptors, the structure of the our bird-flower network lay within the range of the values found for the others networks (Fig. 3). The only exception was connectance that is slightly lower in our network.

\section{DISCUSSION}

The relatively high frequency of birds carrying pollen grains on their foreheads, and the high abundance and richness of pollen grains found, suggests that many birds, up to onefifth, have been actively feeding on flowers. Although there is no absolute threshold based on which interaction release can be considered to occur or not, the number of European unspecialized birds that likely fed on flowers does not seem to be rare or anecdotal, suggesting the general occurrence of this phenomenon. We cannot rule out the possibility that some pollen grains detected in very small numbers, might have been loaded indirectly from airborne pollen, bird handling or when birds forage on food sources, other than flowers, resulting in contaminations. In order to facilitate the comparison with previous studies, we considered the presence of any pollen grain found in a sample as evidence that an interaction occurred, similarly to the approach of the Galápagos study (Traveset et al., 2015). The most conservative approach, that is, excluding likely contaminations, removes from our network c. $88 \%$ of the interactions with typical wind-pollinated plants, which might be indeed potential contaminations. Other alternative conservative approach would be removing all the typical wind-pollinated plant species from our network but this would probably be over-conservative since some birds species [e.g. Cyanistes caeruleus (Linnaeus, 1758), Phylloscopus collybita (Vieillot, 1817) and Regulus ignicapilla (Temminck, 1820)] were seen on several occasions actively foraging on flowers of Q. faginea, a typical wind-pollinated plant. Moreover, Quercus spp. pollen loads reach as much as 732 pollen grains in a single sample from a $R$. ignicapilla. Nevertheless, as we collected a small proportion, that is, only a few feathers, from each bird, and only $80 \%$ of the mounting solution was used in the microscopic slides, the pollen grains identified in the slides represent only part of the total number of pollen grains transported by each bird at the time it was sampled.

At least 61 bird species are known to visit flowers or transport pollen in Europe (da Silva et al., 2014; Calviño-Cancela \& Neumann, 2015). However, these records result from anecdotal observations (see da Silva et al., 2014) or from studies either focused on specific time periods or taxonomically restricted groups (Cecere et al., 2011; Ortega-Olivencia et al., 2012; Wood et al., 2014; Calviño-Cancela \& Neumann, 2015), and this is the first community-level assessment quantifying pollen transport by birds in Europe. Our study confirms that pollen transport by European birds is not a rare or anecdotal event but that it is frequent and generalized, confirming the prediction of da Silva et al. (2014). It has been shown that unspecialized European birds can act as legitimate pollinators of both, native (Ortega-Olivencia et al., 2005) and alien plants (Búrquez, 1989). Although the most 
common pollen found was from the alien E. globulus, the vast majority of the pollen types dispersed were native (Fig. 2). Our data set suggest that European birds visit the flowers of very few alien plant species (Table 1), nevertheless they can be important for their establishment if they mitigate the loss of their native pollinators (Traveset \& Richardson, 2014). This may occur for example for E. globulus which has a mixed pollination system by insects and birds on its native range (Hingston \& Potts, 1998; Hingston et al., 2004), or for typical ornithophilous plants such as Fritillaria imperialis L. introduced in Europe from Asia (Búrquez, 1989) or Aloe arborescens Mill. from Africa (da Silva et al., 2014). Entomophilous and ornithophilous plants such as E. globulus can provide a double reward to birds: nectar and pollen. The nectar can be an important source of simple sugars (Cecere et al., 2011). Anemophilous plants, such as Quercus sp. do not produce nectar, and therefore can only provide pollen as a resource for birds. However, the pollen grains can be very important to birds as they contain high levels of proteins and carbohydrates (Roulston \& Cane, 2000). Birds seem to expand their dietary niche to consume these flower resources particularly when the availability of their typical food sources is low, such as insects during the winter (Wolda, 1988).

The comparison of network structure descriptors across multiple studies should be interpreted carefully (Traveset et al., 2016). Nonetheless, it is clear that for most network structure descriptors, the pollen-transport network by taxonomic groups of unspecialized European birds falls within the range of values reported for networks including taxonomic groups of specialized nectarivorous birds and for the Galápagos network, which is also formed by unspecialized nectarivorous (Fig. 3). The diet shift observed in all Galápagos bird species, when compared to the shift observed in $68 \%$ of the bird species in this study suggests that the ecological release is more intense in the Galápagos. This might be explained by the overall lower insect abundance and the most extreme biotic and abiotic environment in the Galápagos, resulting in stronger intra-specific competition for resources and stronger selective pressure to explore alternative resources (Traveset et al., 2015). Alternatively, European birds have a greater diversity of alternative food sources and have a richer insect community competing for flower resources. Both European and Galápagos networks are less specialized $\left(\mathrm{H}_{2}{ }^{\prime}\right)$ than most taxonomic groups of nectarivorous bird networks (Fig. 3); however, the Galápagos presents particularly low levels of specialization, reflecting the stronger interaction release.

The contrasting results of nestedness and modularity between quantitative or binary matrices were also reported for hummingbird networks in Brazil (Vizentin-Bugoni et al., 2016) and highlight the problem of extracting network structure descriptors from binary (presence/absence) interaction data (Banašek-Richter et al., 2004; Blüthgen et al., 2006; Vizentin-Bugoni et al., 2016).

The first pollen-transport network by a continental community of taxonomic groups of unspecialized nectarivorous birds, reveals that interaction release is not an exclusively island phenomena, but it occurs on a much wider geographical area. Nevertheless, European birds show a less pronounced response than the Galápagos bird community to the presence of underexplored flower resources, suggesting that interaction release is stronger on oceanic islands given their poor and disharmonic biota. We detected interaction release in the absence of taxonomic groups of specialized nectarivorous bird community in Europe.

This work represents an important step into quantifying pollen dispersal by European birds; however, much work is still needed in order to fully evaluate the amplitude and ecological relevance of this process. Finally, testing the interaction release hypothesis on other types of mutualistic and antagonistic interactions, and on other communities around the world, will provide us a much better picture about the geographical and ecological relevance of community-level diet shifts. The analysis of bird-flower interaction networks from centre and north Europe will be important to ascertain if the interaction release is restricted to the Mediterranean or if it occurs in the whole continent. Furthermore, it would be particularly interesting to study the ecological release in regions where there is a known lack of whole functional groups, for example, the lack of vultures in Australia is likely to make large animal carcasses available to other potential scavengers. Given the accelerated decline of some animal groups during the current defaunation, it will also be important to know what species will take advantage of new resources released by the extinction of functional groups, such as megafauna (Guimarães et al., 2008; Johnson, 2009).

\section{ACKNOWLEDGEMENTS}

We thank Javier Valverde for sharing the consensus modularity script and Vanessa Mata for commenting on the manuscript. L.P.S. and R.H. were supported by the Portuguese Foundation for Science and Technology - FCT, through grants SFRH/BD/77746/2011 and IF/00441/2013 respectively. R.H. was also funded by the European Union Marie Curie Action FP7-PEOPLE-2012-CIG-321794. Bird sampling was performed under permits n. 126/2013 and 130/ 2014 CEMPA - Instituto da Conservação da Natureza e das Florestas - ICNF.

\section{REFERENCES}

Almeida-Neto, M. \& Ulrich, W. (2011) A straightforward computational approach for measuring nestedness using quantitative matrices. Environmental Modelling \& Software, 26, 173-178.

Banašek-Richter, C., Cattin, M.F. \& Bersier, L.F. (2004) Sampling effects and the robustness of quantitative and qualitative food-web descriptors. Journal of Theoretical Biology, 226, 23-32.

Banza, P., Belo, A.D.F. \& Evans, D.M. (2015) The structure and robustness of nocturnal Lepidopteran pollen-transfer 
networks in a Biodiversity Hotspot. Insect Conservation and Diversity, 8, 538-546.

Bascompte, J., Jordano, P. \& Olesen, J.M. (2006) Asymetric coevolutionary networks facilitate biodiversity maintenance. Science, 312, 431-433.

Bates, D., Mächler, M., Bolker, B. \& Walker, S. (2015) Fitting linear mixed-effects models using lme4. Journal of Statistical Software, 67, 1-48.

Belmonte, J., Pérez-Obiol, R. \& Roure, J.M. (1986) Claves para la determinación de los pólenes de las principales especies melíferas de la Peninsula Ibérica. Orsis, 2, 27-54.

Bersier, L.F., Banašek-Richter, C. \& Cattin, M.F. (2002) Quantitative descriptors of food-web matrices. Ecology, 83, 2394-2407.

Blüthgen, N., Menzel, F. \& Blüthgen, N. (2006) Measuring specialization in species interaction networks. BMC Ecology, 6, 9.

Bolnick, D.I., Ingram, T., Stutz, W.E., Snowberg, L.K., Lau, O.L. \& Paull, J.S. (2010) Ecological release from interspecific competition leads to decoupled changes in population and individual niche width. Proceedings of the Royal Society B: Biological Sciences, 277, 1789-1797.

Búrquez, A. (1989) Blue Tits, Parus caeruleus, as pollinators of the Crown Imperial, Fritillaria Imperialis, in Britain. Oikos, 55, 335-340.

Calviño-Cancela, M. \& Neumann, M. (2015) Ecological integration of eucalypts in Europe: interactions with flower-visiting birds. Forest Ecology and Management, 358, 174-179.

Cecere, J.G., Spina, F., Jenni-Eiermann, S. \& Boitani, L. (2011) Nectar: an energy drink used by European songbirds during spring migration. Journal of Ornithology, 152, 923-931.

Chao, A. (1987) Estimating the population size for capturerecapture data with unequal catchability. Biometrics, 43, 783-791.

Cox, G. \& Ricklefs, R. (1977) Species diversity and ecological release in Caribbean land bird faunas. Oikos, 28, 113-122.

da Silva, L.P., Ramos, J.A., Olesen, J.M., Traveset, A. \& Heleno, R.H. (2014) Flower visitation by birds in Europe. Oikos, 123, 1377-1383.

da Silva, L.P., Pereira Coutinho, A., Heleno, R.H., Tenreiro, P.Q. \& Ramos, J.A. (2016) Dispersal of fungi spores by non-specialized flower-visiting birds. Journal of Avian Biology, 47, 438-442.

Dalsgaard, B., Magård, E., Fjeldså, J., Martín González, A.M., Rahbek, C., Olesen, J.M., Ollerton, J., Alarcón, R., Cardoso Araujo, A., Cotton, P.A., Lara, C., Machado, C.G., Sazima, I., Sazima, M., Timmermann, A., Watts, S., Sandel, B., Sutherland, W.J. \& Svenning, J.-C. (2011) Specialization in plant-hummingbird networks is associated with species richness, contemporary precipitation and quaternary climate-change velocity. PLoS ONE, 6, e25891.

Dormann, C.F. \& Strauss, R. (2014) A method for detecting modules in quantitative bipartite networks. Methods in Ecology and Evolution, 5, 90-98.
Dormann, C.F., Gruber, B. \& Fründ, J. (2008) Introducing the bipartite package: analysing ecological networks. $R$ News, 8, 8-11.

Elton, C. (1927) Animal ecology. Sidgwick and Jackson, London.

Erdtman, G. (1960) The acetolysis method: a revised description. Svensk Botanisk Tidskrift, 54, 561-564.

Guimarães, P., Jr \& Guimarães, P. (2006) Improving the analyses of nestedness for large sets of matrices. Environmental Modelling \& Software, 21, 1512-1513.

Guimarães, P.R., Galetti, M. \& Jordano, P. (2008) Seed dispersal anachronisms: rethinking the fruits extinct megafauna ate. PLoS ONE, 3, e1745.

Guimerà, R. \& Amaral, L.A.N. (2005) Cartography of complex networks: modules and universal roles. Journal of Statistical Mechanics: Theory and Experiment, 2005, P02001.

Heleno, R.H. \& Vargas, P. (2015) How do islands become green? Global Ecology and Biogeography, 24, 518-526.

Heleno, R., Garcia, C., Jordano, P., Traveset, A., Gómez, J.M., Blüthgen, N., Memmott, J., Moora, M., Cerdeira, J., Rodríguez-Echeverría, S., Freitas, H. \& Olesen, J.M. (2014) Ecological networks: delving into the architecture of biodiversity. Biology Letters, 10, 20131000.

Hingston, A.B. \& Potts, B.M. (1998) Floral visitors of Eucalyptus globulus subsp. globulus in eastern Tasmania. Tasforests, 10, 125-139.

Hingston, A., Potts, B. \& McQuillan, P.B. (2004) The swift parrot, Lathamus discolor (Psittacidae), social bees (Apidae), and native insects as pollinators of Eucalyptus globulus ssp. globulus (Myrtaceae). Australian Journal of Botany, 52, 371-379.

Hintze, J.L. \& Nelson, R.D. (1998) Violin plots: a box plotdensity trace synergism. American Statistician, 52, 181-184.

del Hoyo, J., Elliott, A., Sargatal, J., Christie, D.A. \& deJuana, E. (eds) (2016) Handbook of the birds of the world alive. Lynx Edicions, Barcelona. http://www.hbw.com/.

Johnson, C.N. (2009) Ecological consequences of Late Quaternary extinctions of megafauna. Proceedings of the Royal Society B: Biological Sciences, 276, 2509-2519.

Jordano, P. (1987) Patterns of mutualistic interactions in pollination and seed dispersal: connectance, dependence asymmetries, and coevolution. The American Naturalist, 129, 657-677.

Kapp, R.O. (1969) How to know pollen and spores. W. C. Brown Co, Minnesota.

Keane, R.M. \& Crawley, M.J. (2002) Exotic plant invasions and the enemy release hypothesis. Trends in Ecology and Evolution, 17, 164-170.

Louchart, A., Tourment, N., Carrier, J., Roux, T. \& MourerChauviré, C. (2008) Hummingbird with modern feathering: an exceptionally well-preserved Oligocene fossil from southern France. Naturwissenschaften, 95, 171-175.

Maruyama, P.K., Vizentin-Bugoni, J., Oliveira, G.M., Oliveira, P.E. \& Dalsgaard, B. (2014) Morphological and spatio-temporal mismatches shape a neotropical savanna plant-hummingbird network. Biotropica, 46, 740-747. 
Mateus, J. (1989) Pollen morphology of Portuguese Ericales. Revista de Biologia, 14, 135-208.

Mayr, G. (2004) Old World fossil record of modern-type hummingbirds. Science, 304, 861-864.

Mayr, G. \& Wilde, V. (2014) Eocene fossil is earliest evidence of flower-visiting by birds. Biology Letters, 10, 1-4.

Moore, P.D. \& Webb, J.A. (1978) An illustrated guide to pollen analysis. Hodder and Stoughton, London.

Oksanen, J., Blanchet, F.G., Friendly, M., Kindt, R., Legendre, P., McGlinn, D., Minchin, P.R., O’Hara, R. B., Simpson, G.L., Solymos, P., Stevens, M.H.H., Szoecs, E. \& Wagner, H. (2016) Vegan: community ecology package. R package version 2.4, http://cran.r-project.org/package=vegan.

Ortega-Olivencia, A., Rodríguez-Riaño, T., Valtueña, F.J., López, J. \& Devesa, J.A. (2005) First confirmation of a native bird-pollinated plant in Europe. Oikos, 110, 578590.

Ortega-Olivencia, A., Rodríguez-Riaño, T., Pérez-Bote, J.L., López, J., Mayo, C., Valtueña, F.J. \& Navarro-Pérez, M. (2012) Insects, birds and lizards as pollinators of the largest-flowered Scrophularia of Europe and Macaronesia. Annals of Botany, 109, 153-167.

Queiroz, P.F. (2012) Morfologia polinica das Cistaceae portuguesas. Terra Scenica, Lisbon.

R Core Team (2016) R: a language and environment for statistical computing. R Foundation for Statistical Computing, Vienna, Austria. http://www.r-project.org/.

Refsnider, J.M., Des Roches, S. \& Rosenblum, E.B. (2015) Evidence for ecological release over a fine spatial scale in a lizard from the White Sands formation. Oikos, 124, 16241631.

Reille, M. (1992) Pollen et spores d'Europe et d'Afrique du nord. Laboratoire de Botanique Historique et Palynologie, Marseille.

Roulston, T. \& Cane, J. (2000) Pollen nutritional content and digestibility for animals. Plant Systematics and Evolution, 222, 187-209.

Traveset, A. \& Richardson, D.M. (2014) Mutualistic interactions and biological invasions. Annual Review of Ecology, Evolution, and Systematics, 45, 89-113.

Traveset, A., Olesen, J.M., Nogales, M., Vargas, P., Jaramillo, P., Antolín, E., Trigo, M.M. \& Heleno, R. (2015) Birdflower visitation networks in the Galápagos unveil a widespread interaction release. Nature Communications, 6, 6376.

Traveset, A., Tur, C., Trøjelsgaard, K., Heleno, R., CastroUrgal, R. \& Olesen, J.M. (2016) Global patterns of mainland and insular pollination networks. Global Ecology and Biogeography, 25, 880-890.

Tylianakis, J.M. (2008) Understanding the web of life: the birds, the bees, and sex with aliens. PLoS Biology, 6, 02240228.

Valdés, B., Díez, M.J. \& Fernández, I. (1987) Atlas polínico de Andalucía occidental. Instituto de Desarrollo Regional, Universidad de Sevilla, Excma, Diputación de Cádiz, Cádiz.

Valverde, J., Gómez, J.M. \& Perfectti, F. (2016) The temporal dimension in individual-based plant pollination networks. Oikos, 125, 468-479.

Vizentin-Bugoni, J., Maruyama, P.K., Debastiani, V.J., da Duarte, L.S., Dalsgaard, B. \& Sazima, M. (2016) Influences of sampling effort on detected patterns and structuring processes of a Neotropical plant-hummingbird network. Journal of Animal Ecology, 85, 262-272.

Whittaker, R.J. \& Fernández-Palacios, J.M. (2007) Island biogeography. Oxford University Press, Oxford.

Wolda, H. (1988) Insect seasonality: why? Annual Review of Ecology and Systematics, 19, 1-18.

Wood, M.J., Morgan, P.J., Webb, J.C., Goodenough, A.E., Chambers, F.M. \& Hart, A.G. (2014) Exploring the prevalence and diversity of pollen carried by four species of migratory Old World warbler (Sylvioidea) on arrival in the UK. Bird Study, 61, 361-370.

\section{SUPPORTING INFORMATION}

Additional Supporting Information may be found in the online version of this article:

Appendix S1 Network excluding samples with less than five pollen grains.

\section{BIOSKETCH}

Luis P. da Silva is a final year PhD student at the Department of Life Sciences from University of Coimbra, Portugal. His areas of interest are biodiversity, ecosystem services and conservation of terrestrial ecosystems, especially of birds.

Author contributions: L.P.S., J.A.R. and R.H.H. conceived the idea; L.P.S., A.P.C. and P.Q.T. collected the data; L.P.S. and R.H.H. conducted the statistical analysis; L.P.S. led the writing and all other authors contributed to revisions.

Editor: Pablo Vargas 